MedieKultur | Journal of media and communication research | ISSN 1901-9726

Article - Theme section

\title{
Independent podcasts on the Apple Podcasts platform in the streaming era
}

\section{Freja Sørine Adler Berg}

MedieKultur 2021, 70, 110-131

Published by SMID | Society of Media researchers In Denmark | www.smid.dk The online version of this text can be found open access at www.mediekultur.dk

\begin{abstract}
This article investigates independent podcasts created outside traditional institutions (Markman, 2012) on the world's largest podcast platform, Apple Podcasts, in the context of streaming media. Through a quantitative content analysis of 552 Danish podcasts, the study offers insights into independent podcasting, its medium grammar and content (Meyrowitz, 1998), and the conditions by which independent podcasters navigate in a liminal space between traditional radio and online participatory practices (Berry, 2016; Markman, 2012). The analysis shows that the predominant parts of independent podcasts are conversations and interviews about personal, self-reflective stories and mainstream hobbies such as football, films, and television. These podcasts are less time-consuming to produce than crafted audio (McHugh, 2016) about research-heavy topics. The oversupply of conversations and interviews about personal stories and mainstream hobbies further suggests that independent podcasters are influenced by the mainstreaming and commercialisation of podcasting, including streaming platforms such as Spotify and Amazon adding podcasts to their services, and podcast platforms such as the Danish paid subscription podcast platform Podimo, adopting the curated content distribution model known from Netflix.
\end{abstract}


Article: Independent podcasts on the Apple Podcasts platform in the streaming era

\author{
Keywords \\ Independent podcasts, Apple Podcasts, streaming platforms, podcasts, quantitative \\ content analysis
}

\title{
Introduction
}

Independent podcasting is an inevitable and rapidly growing phenomenon in today's media landscape, including in Denmark, a small language area, yet with high levels of podcast production and consumption (e.g. Newman \& Gallo, 2020, p. 9). Going through Apple Podcasts - currently the largest and most commonly used podcast archive (e.g., Newman \& Gallo, 2020, p. 10; Spinelli \& Dann, 2019, p. 223) - in May and June 2020, I identified 552 Danish-language' independent podcasts (about 25 pct. of all Danish podcasts). In contrast to broadcast radio and legacy media content, anyone can freely produce an independent podcast using their own microphone or smartphone, free editing software, and open-source platforms, without gatekeeping (such as Apple Podcasts) for distribution. Independent podcasters thus navigate in a liminal space between traditional radio and online participatory practices (Berry, 2016; Markman, 2012). Historically, independent podcasts have been characterised as super niche, experimental, and a medium with no obligation to please a large, mainstream audience (Berry, 2016; Markman, 2012). But is this true today?

This article investigates the issue by mapping the topics and formats of independent podcasts, and analyses the results according to the specific characteristics of how they are produced and distributed. This implies the drawing of parallels and distinctions between two essentially different types of streaming platforms: Apple Podcasts as an open-source platform, which is the opposite of highly curated and paid subscription platforms such as Netflix, Spotify, Amazon, and Denmark's first paid subscription podcast platform, Podimo. In summary, this article asks: How are the characteristics of independent podcasting reflected in the independent podcasts on the Apple Podcasts platform? How does this shape our understanding of independent podcasts and Apple Podcasts in the context of streaming media?

Podcast production research is primarily qualitative; there are case studies and indepth enquiries about popular podcasts such as Serial (e.g., Berry, 2015; Heise, 2014; Ora, 2018), podcast genres such as fictional storytelling (e.g., Bottomley, 2015; Hancock \& McMurtry, 2018; Spinelli \& Dann, 2019), narrative journalism (Lindgren, 2016; McHugh, 2016), and conversational podcasts (e.g., Collins, 2018). Podcast listening habits have primarily been quantitatively documented, by for instance Monica Chadha, Alex Avila, and Homera Gil de Zúñiga (2012), Steven McClung and Kristine Johnson (2010), and Lisa Perks and Jacob Turner (2018). These are all important contributions to the emerging field of

1 In the following, I will refer to Danish-language podcasts simply as Danish podcasts. 
podcast studies, and to the understanding of this newer form of media practice, content, and consumption. However, quantitative enquiries of podcast production - specifically independent podcast production - are absent, save for two web-based questionnaires which examined the demographic characteristics and motivations of English-language independent podcasters (Markman, 2012; Markman \& Sawyer, 2014). Two studies of funding models for independent podcasters in English-speaking countries have also been carried out (Crofts et al., 2005; Quirk, 2015). The most extensive quantitative podcast data available is provided by Edison Research (2019) and Podtrac (2021), which includes all types of US podcasts, and thus does not differentiate between independent and institutional podcasts, i.e., podcasts produced by public service, cooperative, or public institutions. The data from Edison Research and Podtrac show that comedy, current events, education, culture, and sports are the most listened-to podcast content. In a national context, personal stories and true crime are most common on Podimo, while culture, society and current events dominate the Danish public service talk radio stations Radio 4 and Radio LOUD. ${ }^{2}$

In the following sections, I present a theoretical framework for investigating independent podcasts on Apple Podcasts, arguing that independent podcasting is a streaming medium, traditional radio, and a participatory media practice.

\section{Podcasts as a streaming medium}

When the word "podcasting" was invented in 2004, it referred to the process of downloading a file via the internet to a computer and transferring it to an MP3 player (Berry, 2016). Since then, smartphone and mobile networks have replaced computers and MP3 players, giving ubiquitous access to the streaming of large amounts of data at an affordable price. The practice of downloading and building a podcast library for later use is outdated (Perks \& Turner, 2018; / Ægidius, 2017), and instead podcast streaming is booming (Slots- og Kulturstyrelsen, 2019). Today, podcasts are always available, and can be accessed from all over the world at a time of one's own choosing. Also, identically to other streaming media, podcast episodes are available in a serialised archive to which new episodes are constantly added. This creates seriality in production as well as consumption practice (Saabye, 2020; Sterne et al., 2008). Podcasts increasingly affect people's everyday lives in the same way as other streaming media. When released weekly or biweekly for several years - for instance, the US podcast My brother, my brother \& me (2020) has gone out nearly every week for the last ten years - they function both as a weekly habit (Perks \& Turner, 2018; Saabye, 2020), and as an archive from which several episodes can be binged. Yet, in comparison with podcast prevalence in Denmark (Slots- og Kulturstyrelsen, 2019) and the proliferation of music, film, and television streaming research (e.g., Andersen,

2 Data from the Danish Broadcasting Corporation's talk radio station P1 is not included here as the publisher tags each podcast episode instead of each podcast title. 
2019; Burgess \& Green, 2018; Lotz, 2017), there is a lack of literature on podcasts as a streaming medium, which the present study intends to address.

We see a mutual influence between podcast platforms and other streaming platforms, as podcast platforms steadily adopt tendencies from television, film, and music streaming platforms, while these platforms also integrate podcasts. To provide a few significant examples: The previously music-only platform Spotify added podcasts as an open feature of their application in October 2018 (Holt, 2018) and signed its first exclusive contract with a podcaster in May 2020 (Cridland, 2020a). Similarly, the video, audiobook, and music streaming service Amazon added podcasts, including exclusive shows, to their audio catalogue in September 2020 (Cridland, 2020b). The podcast medium thus provides a focal point for examining how streaming services in general are changing.

I will shortly describe the relevant features of Apple Podcasts in order to draw comparisons with other streaming platforms. Due to their lack of financing, as I will explain below, independent podcasters tend to use distribution platforms such as Apple Podcasts with no gatekeeping or distinguishing between institutional and independent podcasts. Based on open RSS technology, Apple Podcasts embeds one of independent podcasting's key attractions. It constitutes the foundational architecture of podcasting and remains the largest podcast archive globally and the most used so-called "podcatcher" (Cridland, 2020a; Spinelli \& Dann, 2019, p. 313). Apple Podcasts is also the default podcast platform for podcasters and listeners in Denmark, which is due mainly to the fact that Apple holds the highest share of the Danish smartphone market (StatCounter, 2020), and Apple Podcasts has been a pre-installed app on all iPhones since 2014 (Bottomley, 2015, p. 164). It is thus the most obvious directory for the purpose of mapping independent podcasts in Denmark. The platform does not offer personalised user recommendations: Its only curation is to feature the most popular podcasts and the algorithm-based category "Listeners have also subscribed to". It collects detailed user data to be sold to distributors and advertisers, but, in contrast to the commercial logic of open platforms such as YouTube (Burgess \& Green, 2018), it does not (yet) expose its users to advertisements.

\section{The characteristics of independent podcasts on Apple Podcasts}

As a mobile, on-demand archive medium, podcasts are characterised by intimacy, because the listener chooses the podcast content and most often listens via headphones (e.g., Berry, 2006, 2016). Podcasts share characteristics with radio, as the primary code by which both radio and podcasts communicate is speech (Crisell, 1986, p. 4).

According to UK podcast researcher Richard Berry $(2006,2016)$, a distinctive subcategory of independent podcasts is defined as free for anyone with internet access to produce, distribute, and consume. Similarly, Berry's US colleague Kris Markman (2012, p. 552) defines independent podcasts as unaffiliated with "a pre-existing traditional media program or outlet". Consequently, independent podcasters are not (usually) radio professionals, but individuals and groups outside traditional institutions who use platforms 
with no gatekeeping. Rendered possible by the reduction in the cost of producing and distributing digital content, independent podcasters and listeners are offered the liberty of deeply immersing themselves in niche topics, personal stories, narratives, and sound experiments; and they are able to interact about these topics, stories, and experiments in various, unpredictable ways (Markman, 2012). As such, independent podcasts can be regarded as user-generated content, or "produsage" (Bruns, 2008), grounded within a participatory media culture in which producers and consumers, "old" and "new" media, interact with each other (Jenkins et al., 2015). Independent podcasts thus sit in a liminal space between traditional radio and online participatory media, as they are sonically influenced by (broadcast) radio yet rooted in open-source participatory media practices and niche online communities (Berry, 2006, 2016; Markman, 2012; Markman \& Sawyer, 2014; Spinelli \& Dann, 2019, p. 124). Similar to YouTubing, Instagramming and blogging, independent podcasting is a personalised medium, and a place of self-expression. As political theorist Jodi Dean (2012, p. 140) observes: "Participation becomes indistinguishable from personalization, the continued cultivation of one's person". Similarly, cultivating their identity, self-expression, and being explicitly passionate about their podcast projects are defining features of independent podcasters (Adler Berg, 2021a; Markman, 2012; Spinelli \& Dann, 2019, p. 191).

Independent podcasters seldom earn money from their work, although they seek to generate revenue for podcasting (Markman, 2012; Adler Berg, 2021a, 2021b). Podcast listeners are still reluctant to pay for podcasts, and companies are cautious about sponsoring podcasts (Spinelli \& Dann, 2019, p. 44, p. 303; Sullivan, 2018). This is also the reality for popular English-language podcasts with a much larger audience than Danish podcasts. The present study indicates the same thing: For Danish independent podcasters, only 39 podcasts ( $7 \mathrm{pct}$. of the 552 podcasts) receive some kind of revenue from live shows, sponsors or advertisers, paid collaborations, foundation grants, or a combination of these funding models, while 76 podcasts ( $13.8 \mathrm{pct}$.) ask for listener donations.

The dualistic conception of independent podcasts as traditional radio and a participatory media practice described above provides a theoretical framework for analysing the data in this study. As this is an empirical study, however, an applied definition of independent podcasts is required. In practice, "total independence" and "total dependence" do not exist. For this purpose, then, I will use a slight rephrasing of Markman's (2012, p. 552) definition: An independent podcast has not undergone any kind of gatekeeping and is unaffiliated with pre-existing traditional institutions.

I will describe the methodology for mapping the medium grammar and content of independent podcasts on Apple Podcasts in the following sections. The results of the mapping are then examined in light of the theoretically outlined characteristics of independent podcasts. 


\section{Methodology: Quantitative content analysis}

In order to research the independent podcasts on the Apple Podcasts and how these are reflected in the theoretically outlined characteristics of independent podcasting, this article aims to map Danish independent podcasts in terms of their medium grammar and content. A quantitative content analysis (Eskjær \& Helles, 2015) of all Danish independent podcasts is conducted. Content analysis consists of three steps-sampling, coding, and analysing (Eskjær \& Helles, 2015, p. 41), and quantifies the presence of a set of - typically predefined - values (Eskjær \& Helles, 2015, p. 67; Bryman, 2012, p. 183). Predefined theoretical values, however, cause the risk of inventing a system of values that may not reflect the population (McQuail, 2010, p. 362). I could have simply used Apple Podcasts' categories as the predefined values, and/or used the podcasters' own categorisations of their podcasts on Apple Podcasts, however, the categorisations on Apple Podcasts are unreliable, as podcasters often tag their content in multiple categories to increase their chances of being discovered by listeners (Misener, 2018). Instead, I developed the coding values inductively; that is, based on the empirical data. To illustrate the analytical benefit of this strategy and how it reveals a more nuanced set of categories compared to Apple Podcasts' categorisation system, I will use the example of the Naturpod podcast (transl. Naturepod). It is categorised as "Leisure" on Apple Podcasts, but it specifically explores outdoor equipment, trekking tours, and living in nature. I thus coded it as "Outdoor".

Before delving into the coding process, I will review the sampling process step by step, as it reflects a major challenge for the podcast medium, namely discoverability (Berry, 2016; Swiatek, 2018; Spinelli \& Dann, 2019, p. 211). The sampling process also reflects the essential methodological difficulties of studying content on open-source platforms.

\section{Sampling through the Apple Podcasts platform}

As there are 1,379,957 podcast titles (Newman \& Gallo, 2020, p. 8), and counting, available on Apple Podcasts, I presumed that the most effective and accurate way to sort out all Danish independent podcasts was to generate a list of all Danish podcast titles on Apple Podcasts via Apple's API (application programming interface). This list did not include all Danish podcasts on Apple Podcasts, however (presumably because of multiple or missing language tags by podcasters). Consequently, I had to sample manually.

On 15 May 2020, I began scrutinising the 19 main categories and related subcategories on Apple Podcasts. I soon discovered that the category "Listeners have also subscribed to" contained podcast titles which were absent in the 19 main categories. I therefore reviewed this category for each Danish podcast (both institutional and independent). Podcasts were sampled if they matched the applied definition described above (i.e., no gatekeeping or affiliation with pre-existing traditional institutions). As the only researcher, however, it was ultimately I who decided whether each podcast matched the definition and was thus to be included in the sample. The sample - and thus the results - could 
therefore possibly vary slightly if sampled by a different researcher. The main results, however, would remain the same.

After comparing the API generated list with my manually generated sample, I judged that it was complete and marked the ending of the sampling period as 15 June 2020. Given that podcast is an archive medium, I included podcasts regardless of their publication date. Given that podcast is a serialised medium, I excluded podcasts with less than three episodes, as one or two episodes do not comprise a series.

\section{Coding}

With the list of the final sample in hand, I had to decide whether to code a representative sample or the entire population. Striving to map as many Danish independent podcasts as possible, I decided to code the entire population according to the key variables, medium grammar and medium content.

Each medium constitutes a unique communication setting in which form and content are closely linked and influence one another mutually - developed by Marshall McLuhan (1964) and later Joshua Meyrowitz (1998), who argue that a medium is "a type of setting or environment that has relatively fixed characteristics that influence communication in a particular manner" (ibid., 103). The form and content of podcasts (as well as the production and reception of podcasts - see Waldmann, 2020) thus cannot be separated. Llinares et al. (2018), Spinelli and Dann (2019), Bottomley (2020), and McHugh (2017), among many other podcast academics, have explored podcast and podcasting as a "new type of social "place" whose influence cannot be reduced to the content of the messages that flow through the net" (Meyrowitz, 1998, p. 106). It is not the aim of this article to define independent podcast as a medium environment, however, but to quantitatively analyse specific characteristics of independent podcasts on the Apple Podcasts platform. Meyrowitz' (1998) notions of medium grammar and medium content are thus useful in order to distinguish between the two. According to Meyrowitz, medium content is transferable between media. For instance, "sports" can be the content of other media than podcasts. Medium content is the message that is carried by the medium; it is "aspects of communication that are not specific to specific media" (Meyrowitz, 1998, p. 98). Medium grammar, on the other hand, involves the use of production variables within each medium which can be manipulated to alter perceptions of the medium content (Meyrowitz, 1998, p. 99). Although some medium grammar variables operate in more than one medium - for instance, television and film incorporate both photography and audio - they are generally specific to the medium. The grammar variables for podcasts are speech recording, sound reportage, and sound editing, among others. These variables stage the podcast content using voice, silence, sounds and music. While words are a human invention, sounds manifest the presence of something else, by indicating the objects creating the sounds (Crook, 2011, p. 11, p. 152; Crisell, 1986, p. 43, p. 127). Applied to the coding of podcast grammar, this means that e.g. reportage (as a coding category) focuses on acoustically portraying 
on-location environments and events. Conversely, conversation, monologue, debate, and interview focus on spoken words. Magazine, crafted audio, and narration are all edited audio productions. Crafted audio explores dramaturgy and composed sonic aesthetics, to fully immerse the audience in another world (McHugh, 2017). As I coded the medium grammar of the podcasts, studies of conversational live-on-tape podcasts (Collins, 2018; Meserko, 2015; Markman \& Sawyer, 2014; McHugh, 2017), non-fictional storytelling (Heise, 2014; Lindgren, 2016; Dowling, \& Miller, 2019), and fictional storytelling (Bottomley, 2015; Hancock \& McMurtry, 2018; Spinelli \& Dann, 2019, p. 141) came to mind. These studies thus theoretically embedded the code values that were otherwise developed by induction.

The coding of each podcast is based on sporadic listening to at least three episodes (a total of more than 1600 episodes). Each podcast is coded according to its main content focus and grammar (determined by an overall assessment based on listening to a minimum of three episodes), the podcast title, description, and show notes. In some podcast cases, the medium grammar is a combination of conversations and interviews, which prompted me to make an assessment of whether most episodes were conversations between the hosts or interviews with guests. This of course reduces the reliability of the coding. The overall predominance of conversation and interview podcasts, however, as we will see in the following analysis, remains a reliable finding.

It is of course evident, as Eskjær and Helles (2015, p. 52) point out, that technology causes unstable sampling units and populations in media research. Podcasts, in particular, are volatile and fluctuating, as they are continuously added to, edited, or deleted from online archives. The population of this study is therefore unique to the period in which it is sampled. The results provide a snapshot of a moving picture, so to speak. Despite this, the significant findings of this study, such as the prevalence of conversation and interview podcasts about self-development or football, may apply to populations sampled a few years before or after this particular study, or to independent podcasts in other (Nordic) countries.

Lastly, it is important to note that the replicability of the study would be improved if the description of coding values and the coding itself were not conducted by the same researcher (Krippendorff, 2004, p. 131), or if several researchers coded the empirical data and discussed and resolved discrepancies via an intercoder reliability test (Eskjær \& Helles, 2015, p. 77). As there were no resources for either of these methodological practices, I have strived to describe coding values and coding procedures as accurately as possible in the coding manual to ensure that the study can be repeated by another coder. 


\title{
Analysis of medium grammar and medium content
}

\begin{abstract}
Hello, and welcome! This programme is for people who are too busy to listen to all the new Danish podcasts. We highlight the best of the best podcasts. Today, we will play clips from the true crime podcast The Horror Cabin, the internet mogul Sara Monica gives advice about how to become a successful influencer, and we will visit a letterbox podcast to collect some good tips about sex and relationships!
\end{abstract}

(Det tomme magasin, DR P3, June 25, 2019)

The quote above is from the podcast Det tomme magasin (transl. The Empty Magazine) which has been published since June 2019 by P3, the Danish Broadcasting Corporation's youth radio channel. It consists of satirical comments and fictional sketches about the topics, formats and production of independent podcasts. Self-help, true crime, entrepreneurship, influencing, unstructured chat between two amateur hosts, interviews with pseudo-celebrities, and perpetual monologues are presented as typical of independent podcasts, and ridiculed. A broadcast channel satirically programming independent podcasts on a weekly basis indicates that (at least some) independent podcasts have become a part of popular culture, and thus powerful. Listeners to P3 have an impression of how independent podcasts sound, what they are about, and "get it" when they are made fun of. But does Det tomme magasin truthfully reflect the gist of independent podcasts? This is the subject of the following analysis, in which I will first discuss the medium grammar and then the medium content of Danish independent podcasts.

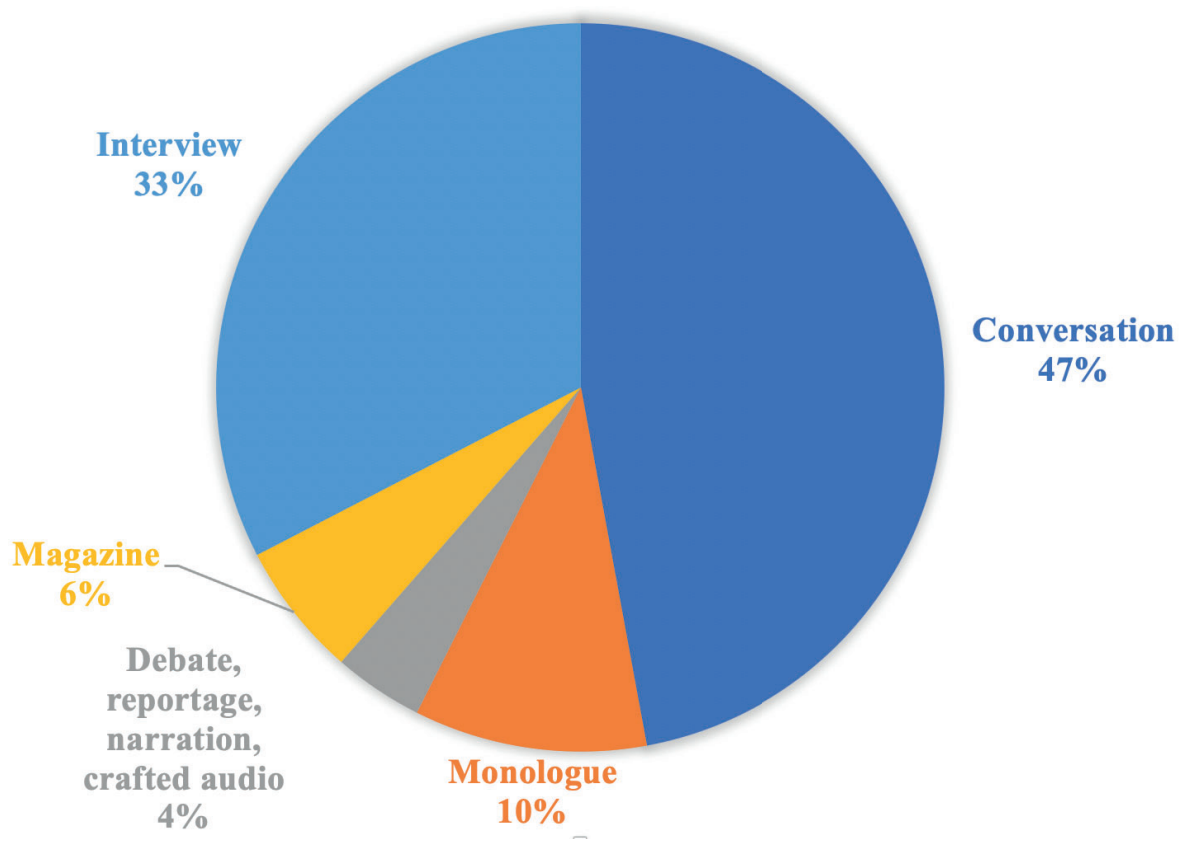

Figure 1: The medium grammar of Danish independent podcasts. 


\section{Medium grammar-Record, speak, upload!}

Considering the economic conditions of independent podcasting, it is not surprising that the cheap and easy production of conversation and interview podcasts combined constitute $80 \mathrm{pct}$. of the study population, as illustrated by Figure 2. Conversations and interviews as the default medium grammars for independent podcasters further indicate the strengths and weaknesses of the podcast medium. The straightforward structure of these grammars highlights the intimacy with the listeners, and they often function well when hosts and guests provide what we might call "good chemistry". Conversely, listeners will stop listening or quickly become bored if they sense "bad chemistry", or if the hosts or guests are not willing to reveal something new, preferably challenging and difficult, about themselves and their lives (Collins, 2018, p. 232). The persons speaking are just as (or even more) crucial to the podcast as the topic discussed in the podcast. The high percentage of conversations and interviews further implies that scripts are less common in independent podcasts than in talk radio (although this might be delivered as if it were not scripted) (Crisell, 1986, p. 55). Conversations and interviews require little preparation when it comes to scripting and editing, and this allows for the frequent and continual release of new episodes, thus giving rise to the quality of seriality.

Fifty-three percent of all Danish independent podcasts are hosted by two people or more. With no funding, as mentioned above, it is beneficial for independent podcasters to disperse the workload between several podcasters. This is further documented by the finding that only $11 \mathrm{pct}$. of independent podcasts are monologues (a single person talking with or without a script). Only $0.7 \mathrm{pct}$. are debates (several hosts and/or guests - more than two - involved in a discussion in which opposing arguments are put forward). Independent podcasting is thus seldom an online space for discussing conflicting opinions, compared to Danish public service talk radio, in which we find at least one hour of debate each day ${ }^{3}$.

Combined, 90 pct. of the sample is pure speech (i.e., conversation, interview, monologue, and debate), whereas reportage (including radiogenic commentary on public events such as sports coverage [Crisell, 1986, p. 128]) is rare in independent podcasts. The same applies for crafted audio and narration which also have radiogenic traits (Bottomley, 2020). We might interpret these results as independent podcasters' lacking interest, technical skills, or time to work with sound editing; in any case, the results show that independent podcasts are not very radiogenic. To a greater extent, they are an expression of a participatory media practice in which the barriers to entry are low and everyone with a smartphone can press record and upload their speech to the internet.

3 For example, see https://www.dr.dk/radio/p1/p1-debat, https://www.radio4.dk/program/frontlinjen/ and https://radioloud.dk/shows/touche/ 


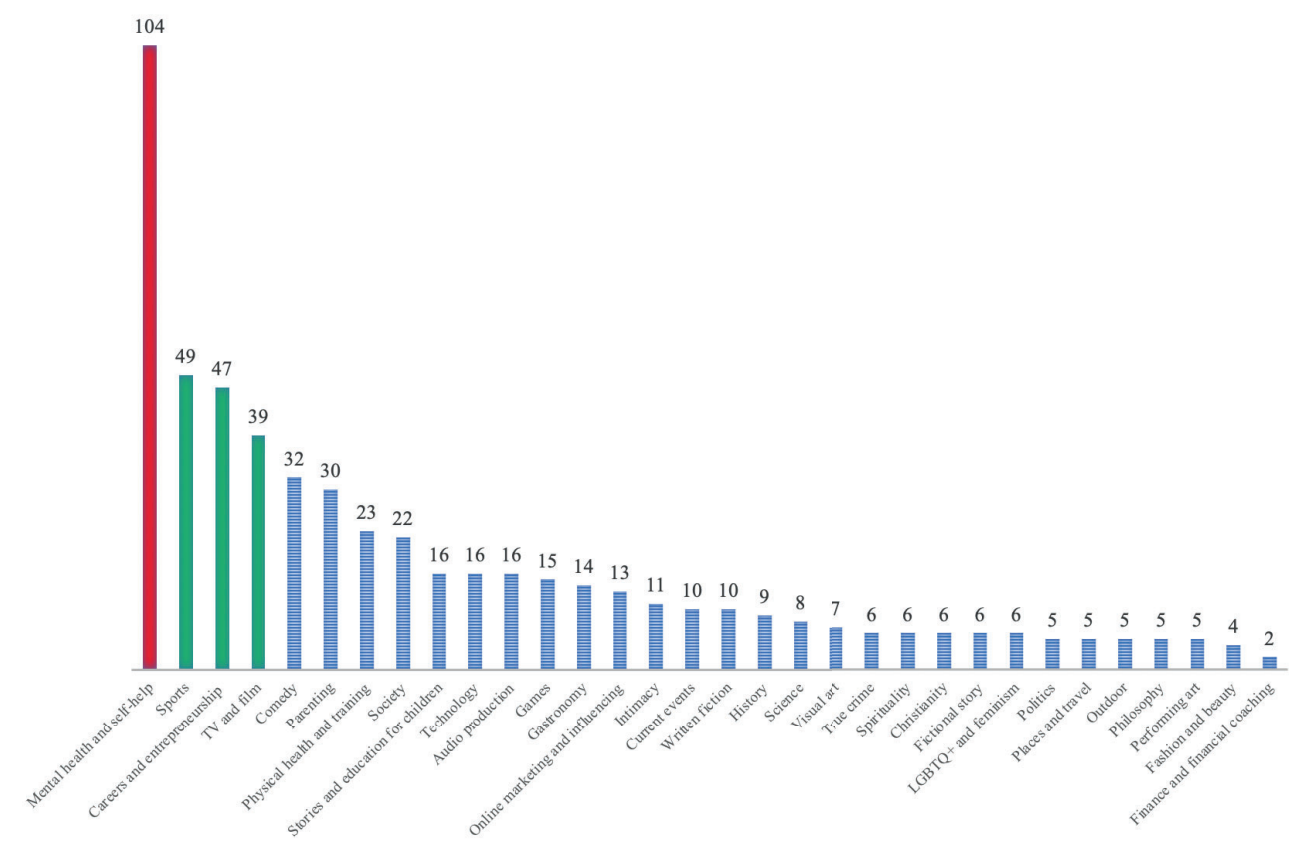

Figure 2: The head (red column, 104 podcasts), the neck (green columns, 135 podcasts in total divided between three categories), and the long tail (blue columns, 313 podcasts in total divided between 28 categories) of the medium content (32 categories in total).

\section{The "head" of medium content-Personal, private, intimate}

19 pct. of all Danish independent podcasts are about mental health and personal journals. This is the largest medium content category - the "head" of the medium content graph. ${ }^{4}$ Incontestably, podcasts documenting the hosts' lives are highly popular podcast content, for several reasons. Talking about oneself requires no preparation, and a setting in which one has control over one's own narrative invites self-reflexivity and personal, honest, and intimate stories. With no restrictions and gatekeeping, independent podcasting allows boundless and unscripted self-examination, and episodes can be as long and as often as the podcaster sees fit, enabling an even more intimate relationship between host and listener.

Personal stories and self-expression are also characteristic in participatory media practices such as YouTubing, Instagramming and blogging (Dean, 2012). Similarly, independent podcasts are deeply personalised and self-cultivating. In particular, mental health and personal journal podcasts are attributed to the contemporary culture of confession and self-help, in which the differences between famous and ordinary people are blurred, and accessibility, relatability, and personal experience triumph over professional expertise (Collins, 2018, p. 227). The podcasts in the head offer what Collins (ibid., p. 230) describes

4 In comparison, Podimo offers 24 personal stories (22.9 pct. of the platform's exclusive podcast content). 
as the "distance anonymous vicarious counselling" of mental health issues and personal problems, either by delivering direct advice to help the listeners to overcome a painful situation, or by revealing their own stories and making the listeners feel less alone (ibid.). Indeed, mental health and personal journal podcasts contribute to a cultural era of intimacy.

Finally, mental health and personal journal podcasts are also radiogenic, as traditional radio advice shows are similarly preoccupied with mental health issues (Crisell, 1986, p. 61) - exemplified in a Danish context by the persistent popularity of the radio programme Mads og monopolet (as from 2021, Sara og monopolet) published since 2003 by the Danish Broadcasting Corporation. The functions of traditional phone-in programmes (ibid., p. 189) are revived and enhanced, as podcast hosts and guests perform their personalities, delve into personal challenges and are encouraged to talk about themselves, their feelings, and attitudes to life. The affective force of oral/aural media is particularly suitable for personal journals (McHugh, 2017). As podcast academic Stacey Copeland (2018, p. 222) states, the podcasters share "their personalities with the public ... expressing the human understanding of the sound of the voice as an indisputable part of both an embodied self and a performative identity". As Professor of American studies, Eva-Sabine Zehelein (2019, p. 146), reminds us: "We, as audience, are sneaky earwitnesses".

Two popular podcasts might illustrate how this widespread content is rooted in both - or somewhere in between - traditional radio and participatory media practices: Fries Before Guys is a podcast about "life, joy, anxiety, confusion, and expectations. It is about you" (description from podtail.com, my English translation). The hosts rely upon relatability and their own personal experiences, and listeners - women in their twenties - provide questions, personal stories, and issues to be discussed in the podcast (Adler Berg, 2021a). Some Fries Before Guys episodes are solely humorous stories from the lives of the podcasters and listeners. These episodes differentiate the podcast from another example of a mental health and personal journal podcast: Perfekt Uperfekt (transl. Perfect Imperfect). This podcast is about more than pure entertainment when the host interviews personalities about "everything that life brings, including anxiety, stress, shame, self-esteem, sex, relationships, weight loss, and health" (description from podtail.com, my English translation).

\section{The "neck" of medium content-Fans of football, films and television}

The "neck" of the medium content graph consists of podcasts about popular interests. Firstly, there are sports podcasts, of which half are football podcasts. Football is the national sport in Denmark, as well as a global phenomenon, and it provides continuous new content that is available on streaming services, thus enabling seriality. Sports are supported by fans and communities: 13 of the 23 football podcasts concern a specific club or tournament. Seriality and fan community also apply to podcasts about television shows and film. Sixteen of the 39 television and film podcasts are specifically related to a specific 
film, television series, or niche genre (e.g., 1980s action movies). Independent podcasters are thus not traditional sports news hosts or film critics, but facilitators of fandom. They are producers of companion content or fan commentary; rereading, recapping, and reviewing existing films or television series, for instance, whether this is popular culture or niche podcasts such as Med dansk tale (transl. With Danish dubbing) which discusses Danish dubbings of Disney films, or Dahlgårds Tivoli Podcast which comments on a Danish soup documentary from 1999. These podcasts are targeted to hyper-specific audiences, and they thus embody the ability of independent podcasting to create and service online knowledge and fan communities.

Sports, film and television series podcasts secondly mirror the widespread streaming culture in Denmark (Slots- og Kulturstyrelsen, 2019), in which especially the younger parts of the population - namely podcasters and podcast listeners - subscribe to streaming services such as Netflix, Viaplay, and Disney+.

The neck of the content graph finally reveals that independent podcasters use the medium as an outlet for discussing their professional lives and careers. They incorporate podcasting into their professions, thereby decreasing the line between the leisure activity of podcasting and their paid occupations. The themes of self-realisation and self-development that are apparent in the mental health and personal journal podcasts recur in the career and entrepreneurship podcasts. The seriality of the podcast medium is also useful for documenting long-term projects and developments - personal as well as professional - step by step, thereby branding their own company, as demonstrated by the famous US entrepreneurship podcast StartUp (Blumberg, 2014). Finally, the category reflects clearly that podcasters - as well as their listeners - are generally highly educated and engaged in their work-life (Markman, 2012, p. 553).

\section{The "tail" of medium content-Comedy, current events and thematic interests}

It seems as convenient to talk about oneself and one's everyday life from a humorous perspective as talking about one's self-development. Comedy was the most popular podcast category in the US in 2019 (Edison Research, 2019), and certain Danish comedy podcasts such as Det vi taler om (transl. What we talk about) gather a large audience each week (podcastindex.dk, 2021). Satire, humour, and narrative sketch shows have always been successful in traditional radio (Crisell, 1986, p. 164). For these reasons, 32 (5.8 pct.) independent comedy podcasts are fewer than expected.

The second most popular content in the US (Edison Research, 2019) was current events, such as The Daily by the New York Times and Global News Podcast by the BBC. Independent podcasts have never been live broadcasted, however - in contrast to ondemand radio - which may be why we only find 1.8 pct. of current events podcasts in the sample. Nor do we find education to be popular independent podcast content, in contrast to US podcasts (Edison Research, 2019; Podtrac, 2021), probably because podcasts produced by (educational) institutions are not included in this study. It should be 
mentioned, however, that many independent podcasts, such as podcasts for children, and podcasts about science and history, allow for de-centralised non-formal education (Swiatek, 2018).

What inevitably catches the eye when examining the tail of the content graph is that it only contains six true crime podcasts, which is remarkably few compared to US data (Edison Research, 2019; Podtrac, 2021), and Podimo (22 true crime podcasts, 20.9 pct. of Podimo's exclusive podcasts), and given the global success of the 2014 podcast Serial and the popularity of the Danish independent true crime podcast Mørkeland (Slots- og Kulturstyrelsen, 2019; podcastindex.dk, 2021). On the other hand, true crime content is time-consuming to produce, as it requires a great deal of background research.

Of the entire sample, $5.4 \mathrm{pct}$. of the podcasts are about parenting. Similar to the mental health and personal journal podcasts, parenting podcasts entail deeply personal stories that open pathways of identification and vulnerable and sensitive issues which fit the conversational and intimate nature of the podcast medium. The 16 podcasts (2.9 pct.) about technology and 13 podcasts (2.4 pct.) about online marketing and influencing might suggest that many independent podcasters are employed in the media, IT, or marketing industry (Markman, 2012, p. 553). Similarly, the 16 podcasts (2.9 pct.) about audio production suggest that many podcasters work with audio media and have access to audio production equipment. Seven podcasts are specifically concerned with the podcast medium (of which four are about technological aspects and three about aesthetic aspects). Only three of the 16 audio production podcasts feature copyright music. This might be due to a lack of money for securing the rights to use a piece of copyrighted music. Radio has always been - and in many cases still remains - a music medium (e.g., Crisell, 1986), but music podcasts are not feasible due to the economic conditions of independent podcasting. Spotify has attempted to address the copyright issues of independent podcasters by allowing podcasters to include full songs in their podcasts (Carmen, 2020), however, these podcasts are solely available to Spotify Premium listeners, and Spotify does not pay the podcasters part of the subscription money.

Finally, many of the podcasts located in the tail of the medium content graph are centred on communities of niche interests, such as games, written fiction, and visual culture. Identity communities based on cultural affinity such as LBGTQ+ are also present in the tail. As observed by academic Lukasz Swiatek (2018, p. 180), these podcasts highlight the ability of independent podcasting to connect distanced publics and create multi-social relationships across podcasters and listeners.

\section{Conclusion and discussion}

The weekly, nationally broadcast radio programme The empty magazine, delivering satirical comments on genre conventions of independent podcasts, suggests that independent podcasts in Denmark have now become popular culture. Independent podcasts differ 
from institutional podcasts as they are produced and distributed freely. They represent a widespread and popular type of user-generated streaming content, but in terms of systematic, quantitative knowledge, we know very little about them. This study has thus mapped all Danish independent podcasts on the largest podcast platform, Apple Podcasts, according to their medium grammar and medium content (Meyrowitz, 1998), and investigated these results according to the specific characteristics of independent podcasting.

My theoretically grounded expectation of the coding was that the independent podcasts, as they are not formalised or institutionalised, would be dispersed among a wide range of audio expressions and niche topics, however, the coding reveals that the same medium grammar and medium content are repeated over and over again: Conversations and interviews about self-development, personal stories and popular entertainment such as football, film, and television. These types of podcasts are easy, less expensive, and less time-consuming to produce over an extended period of time than reportages, narrative audio productions, and research-heavy podcasts about true crime, history, or science, which are mainly absent in the landscape of Danish independent podcasts. McLuhan's (1964, p. 23) quote "The medium is the message" is fulfilled: Certain kinds of medium grammar and medium content are inseparable and recognisable as independent podcasts. Mental health and personal journal podcasts reflect the medium's inherent intimacy and suitability for honest self-reflexivity and relatability. The seriality of the podcast medium and the unlimited duration of episodes also ensure detailed personal revelations and a high degree of intimacy with the listener. The large quantity of sports, television and film podcasts situate independent podcasting as a derivative medium that is a companion to existing media content. Even more importantly, they demonstrate that independent podcasts are not only a participatory media practice, but also specific fan knowledge communities in which the podcasters practice fandom towards a specific object and address fans like themselves.

Another reasonable explanation of these findings is that independent podcasters tend to be focused on gathering audiences rather than on sound. As a consequence of Serial and the prevalence of smartphones, the activities of both producing and listening to podcasts are more than ever visible and accessible, and podcasting is becoming mainstream (Bonini, 2015; Llinares, et al., 2018, p. 6). However, the fact that podcasting is booming does not imply that all podcasts receive many listeners, as Spinelli and Dann (2019, p. 211) note. Chris Anderson's economic model for digital media and entertainment industries (Anderson, 2006) is illustrative in this regard. His model determines that very few products will become commercial hits, while there are a large number of non-hits in a continuous stream due to the low cost of production and distribution of digital content. Thus, according to Anderson, it is evident and inevitable that most Danish independent podcasts gain only a few listeners-in fact, data shows between 0 and 500 listeners (Ziengs, 2019, p. 6). Under these conditions, and considering the ontology of the medium, inno- 
vative or even avant-garde niche podcasts may have a better chance of popularity (i.e. reaching more than 500 listeners) than podcasts seeking to appeal to the widest audience. Maybe a "geeky" podcast about left-handed croquet players, or fountain pens - exemplified by the 400 episodes of the American podcast The Pen Addict - is better off than yet another conventional self-help or football podcast.

The fact that the podcast is reaching higher levels of mainstream cross-over and commercialisation implies that podcasts are added to streaming services such as Spotify and Amazon, while tendencies from audio-visual and music streaming platforms - market logics, algorithms, and recommendation systems from both open-source media platforms such as YouTube and enclosed platforms such as Netflix - are steadily transferred to the emerging podcast market. The booming podcast market and television, film and music streaming platforms are thus mutually shaping each other. What can we learn from investigating the Apple Podcasts platform in this context? The time-consuming sampling of podcasts for this study demonstrates the difficulties of discovering niche podcasts on Apple Podcasts. The platform does not feature personalised user recommendations, and podcast charts on Apple Podcasts and other open-source podcast platforms such as Google Podcast are dominated by a few podcasts affiliated with traditional media institutions, or hosted by well-known personalities. Consequently, it is extremely difficult for unknown podcasters to be discovered, which suggests a demand for new platforms that enable listeners to find new podcasts. Among others, Spotify, Amazon, Google Podcasts, OverCast, Podbean, and Podimo have embraced the opportunity to solve - and monetise - this challenge by developing user recommendations, improved search functions, and interfaces. As more and more podcast platforms engage in improving discovery features and chart ranking systems, Apple Podcasts appears slightly old-fashioned, and the platform will probably change its features and/or consider a subscription model in the near future. In 2020 it launched several exclusive shows, including Apple News Today, which is the first daily news podcast produced by a major platform company (Newman \& Gallo, 2020, p. 21), and Oprah Winfrey's show Oprah's Book Club.

Paid subscription platforms provide a barrier for new listeners, however, and podcasters on, for instance Podimo (Adler Berg, 2021a), are in danger of losing listeners who are unwilling to pay for podcast content. What is distinct about paid subscription platforms for podcasts in comparison to, for instance, paid subscription platforms for films and series (e.g., Netflix, HBO, Disney+) is the origin of podcasts as user generated content. Podcasting started out as, and in many cases remains, a DIY medium distributed via open RSS feeds. We therefore now see a clash between open podcast platforms, represented by Apple Podcasts, and paid subscription platforms. Open platforms encourage new experimental audio practices, create communities around the world and offer opportunities for connecting listeners and distanced publics (Swiatek, 2018, p. 180; Spinelli \& Dann, 2019, p. 211). Paid subscription platforms unavoidably hinder this bridging and transform the very foundations of the podcast medium. 
This study is pioneer work within the field of podcast studies. It will certainly be interesting to conduct a similar enquiry a few years from now, or in other countries, to identify national differences in independent podcast production. What kind of medium content and medium grammar interest podcasters and listeners in countries similar or different to Denmark? In the Spanish independent podcastsphere, David García-Marín and Roberto Aparici (2020) argue that technology and television series are the most prominent medium content, and conversations and monologue the most representative medium grammar. A quantitative enquiry, however, does not validate their assumption. Secondly, with the empirical data already collected, more variables can easily be coded, thus providing us with more knowledge about the production and distribution of independent podcasts. For instance: How often are new episodes published? How many episodes per podcast are published? What is the duration of each episode? What social media platforms are used for community building and distribution? Finally, other methods are necessary to provide more knowledge about Danish independent podcasters. A questionnaire survey is suggested to further map demographic questions such as residence, occupation, and age ${ }^{5}$. Following qualitative studies of what motivates independent podcasters in general (Adler Berg, 2021a, 2021b; Fox et al., 2020; Spinelli \& Dann, 2019), qualitative interviews are needed to qualify and explain the findings presented in this study: Does the high percentage of conversation-based podcasts indicate that independent podcasters are utilising the medium to practise the skill of conversing or to kickstart a career as an interviewer? Why do they avoid experimenting with different styles of audio production and sound composing? What are their motivations to podcast about personal lives and mental health?

Most importantly, the study and subsequent discussion suggest an urgent rethinking of the potential of podcast as a medium. The reliance of independent podcasts on radio's conventions may be hindering it from developing new narrative and audio forms and thus liberating itself from the radio medium.

\section{References}

Anderson, C. (2006). The Long Tail. How Endless Choice is Creating Unlimited Demand. London: Random House Business Books.

Andersen, M.M.T. (2019). Creativity in Television Production - DR3's Channel Strategy. PhD dissertation. Aarhus: AU Library Scholarly Publishing Services. https://doi.org/10.7146/aul.328.222

5 In the present study, only four podcasts were made by children or young people under the age of 18 . This indicates that podcasting is used to a significantly lesser extent than YouTube, for instance, by children and teenagers. 
Adler Berg, F.S. (2021a). The tension between podcasters and platforms: independent podcasters' experiences of the paid subscription model. Creative Industries Journal (14), 1-21. https://doi.org/10.1080/17510694.2021.1890417

Adler Berg, F.S. (2021b). The value of authenticity and intimacy: A case study of the Danish independent podcast Fries Before Guys' utilization of Instagram. (Accepted/In press) Radio Journal: International Studies in Broadcast \& Audio Media, 19(1).

Berry, R. (2006). Will the iPod kill the radio star? Profiling podcast as radio. Convergence, 12(2), 143-162. https://doi.org/10.1177/1354856506066522

Berry, R. (2015). A golden age of podcasting? Evaluating serial in the context of podcast histories. Journal of Radio \& Audio Media, 22(2), 170-178. https://doi.org/10.1080/19376529.2015.1083363

Berry, R. (2016). Podcasting: Considering the evolution of the medium and its association with the word 'radio'. The Radio Journal - International Studies in Broadcast \& Audio Media, 14(1), 7-22. https://doi.org/10.1386/rjao.14.1.7_1

Bonini, T. (2015). The 'second age' of podcasting: Reframing podcasting as a new digital mass medium. Quaderns del CAC, 41(18), 21-30.

Bottomley, A. (2015). Podcasting, Welcome to Night Vale, and the revival of radio drama. Journal of Radio \& Audio Media, 22(2), 179-189. https://doi.org/10.1080/19376529.2015.1083370

Bottomley, A. (2020). SoundStreams. A Cultural History of Radio-Internet Convergence. Michigan: University of Michigan Press. https://doi.org/10.3998/mpub.9978838

Bruns, A. (2008). Blogs, Wikipedia, Second Life and Beyond: From Production to Produsage. Bern: Peter Lang. https://doi.org/10.1080/19331680802664697

Bryman, A. (2012). Social Research Methods. Oxford: Oxford University Press.

Burgess, J.B. \& Green, J.B. (2018). YouTube: Online Video and Participatory Culture (2nd edition). Cambridge: Polity Press. https://doi.org/10.1080/1369118X.2020.1726989

Campbell, G. (2005). There's something in the air: Podcasting in education. Educause Review, 40(6), 32-47.

Chadha, M., Avila, A. \& Gel de Zúñiga, H. (2012). Listening in: Building a profile of podcast users and analysing their political participation. Journal of Inmedium grammarion Technology \& Politics, 9(4), 388-401. https://doi.org/10.1080/19331681.2012.717481

Collins, K. (2018). Comedian hosts and the demotic turn. In D. Llinares, N. Fox \& R. Berry (Ed.). Podcasting: New Aural Cultures and Digital Media (pp. 227-250). Basingstoke: Palgrave Macmillan. https://doi.org/10.1007/978-3-319-90056-8

Copeland, S. (2018). A feminist materialisation of amplified voice: Queering identity and affect in The Heart. In D. Llinares, N. Fox \& R. Berry (Eds.). Podcasting: New Aural Cultures and Digital Media (pp. 209-226). Basingstoke: Palgrave Macmillan. https://doi.org/10.1007/978-3-319-90056-8

Crisell, A. (1986). Understanding Radio. London: Methuen \& Co.

Crofts, S., Dilley, J., Fox, M., Retsema, A. \& Williams, B. (2005). Podcasting: A new technology in search of viable business models. First Monday, 10(9). Retrieved from https://firstmonday.org/article/view/1273/1193

Crook, T. (2011). The Sound Handbook. Oxfordshire, UK: Routledge.

Dean, J. (2012). Whatever blogging. In T. Scholz (Ed). Digital Labor: The Internet as Playground and Factory (pp. 127-146). London: Routledge.

Drotner, K., Jensen, K.B., Poulsen, I., \& Schrøder, K. (1996). Medier og kultur. En grundbog i medieanalyse og medieteori. København: Borgen.

Eskjær, M.F. \& Helles, R. (2015). Kvantitativ Indholdsanalyse. Frederiksberg: Samfundslitteratur. 
Fox, K., Dowling, D.O. \& Miller, K. (2020). A curriculum for blackness: Podcasts as discursive cultural guides, 2010-2020. Journal of Radio \& Audio Media, 27(2), 298-318. https://doi.org/10.1080/19376529.2020.1801687

García-Marín, D. \& Aparici, R. (2020). Domesticated voices and false participation: Anatomy of interaction on transmedia podcasting. Comunicar, 28(63), 97-107. https://doi.org/10.3916/C63-2020-09

Hancock, D. \& McMurtry, L. (2018). 'I know what a podcast is': Post-serial fiction and podcast media identity. In D. Llinares, N. Fox \& R. Berry (Eds.). Podcasting: New Aural Cultures and Digital Media (pp. 81-105). Basingstoke: Palgrave Macmillan. https://doi.org/10.1007/978-3-319-90056-8

Jenkins, H., Ito, M. \& Boyd, D. (2015). Participatory Culture in a Networked Era: A Conversation on Youth, Learning, Commerce, and Politics. New Jersey: John Wiley \& Sons.

Krippendorff, K. (2004). Content Analysis: An Introduction to its Methodology. London: SAGE.

Lindgren, M. (2016). Personal narrative journalism and podcasting. The Radio Journal - International Studies in Broadcast \& Audio Media, 14(1), 23-41. https://doi.org/ 10.1386/rjao.14.1.23_1

Llinares, D., Fox, N. \& Berry, R. (2018). Podcasting: New Aural Cultures and Digital Media. Basingstoke: Palgrave Macmillan. https://doi.org/10.1007/978-3-319-90056-8

Lotz, A.D. (2017). Portals. A Treatise on Internet-Delivered Television. Michigan: Ann Arbor MI, Michigan Publishing.

Markman, K. (2012). Doing radio, making friends, and having fun: Exploring the motivations of independent audio podcasters. New Media \& Society, 14(4), 547-565. https://doi.org/10.1177/1461444811420848

Markman, K. \& Sawyer, C.E. (2014). Why pod? Further explorations of the motivations for independent podcasting. Journal of Radio \& Audio Media, 21(1), 20-25. https://doi.org/10.1080/19376529.2014.891211

McClung, S., \& Johnson, K. (2010). Examining the motives of podcast users. Journal of Radio \& Audio Media, 17, 82-95. https://doi.org/10.1080/19376521003719391

McHugh, S. (2016). How podcasting is changing the audio storytelling genre. The Radio Journal - International Studies in Broadcast \& Audio Media, 14(1), 65-82. https://doi.org/10.1386/rajo.14.1.65_1

McHugh, S. (2017). Memoir for your ears: the podcast life. In B. Avieson, F. Giles and S. Joseph (Eds.). Mediating Memory: Tracing the Limits of Memoir (pp. 104-122). New York \& London: Routledge.

McLuhan, M. (1964). Understanding Media. The Extensions of Man. New York \& London: Routledge.

McQuail, D. (2010). McQuail's Mass Communication Theory, 6th Edition. London: SAGE Publications Ltd.

Meyrowitz, J. (1998). Multiple media literacies. Journal of Communication, 48(1), 96-108. https://doi.org/10.1111/j.1460-2466.1998.tb02740.x

Meserko, V.M. (2015). The pursuit of authenticity on Marc Maron's WTF podcast. Continuum: Journal of Media \& Cultural Studies, 11(2), 796-810. https://doi.org/10.1080/10304312.2015.1073682

Ora, R. (2018). Invisible evidence: Serial and the new unknowability of documentary. In D. Llinares, N. Fox \& R. Berry (Eds.). Podcasting: New Aural Cultures and Digital Media (pp. 107-122). Basingstoke: Palgrave Macmillan. https://doi.org/10.1007/978-3-319-90056-8

Perks, L., \& Turner, J. (2018). Podcasts and productivity: A qualitative uses and gratifications study. Mass Communication and Society, 22(1), 96-116. https://doi.org/10.1080/15205436.2018.1490434

Quirk, V. (2015). Guide to podcasting. Columbia Journalism Review. Retrieved from https://www.cjr.org/tow_center_reports/guide_to_podcasting.php 7

Saabye, S.N. (2020). Podcastlytteren som hverdagskurator : En undersøgelse af podcastlytning som praksisfænomen i hverdagen. PhD dissertation. Aarhus: Aarhus University.

Spinelli, M. \& Dann, L. (2019). Podcasting: The Audio Media Revolution. New York: Bloomsbury Academic. Sterne, J., Morris, J., Baker, M.B. \& Freire, A.M. (2008). The politics of podcasting. The Fibreculture Journal, 13. Retrieved from https://doi.org/10.5040/9781501328671 
Sullivan, J. L. (2018). Podcast movement: Aspirational labour in the formalisation of podcasting as a cultural industry. In D. Llinares, N. Fox \& R. Berry (Eds.). Podcasting: New Aural Cultures and Digital Media (pp. 35-56). Basingstoke: Palgrave Macmillan. https://doi.org/10.1007/978-3-319-90056-8

Swiatek, L. (2018). The podcast as an intimate bridging medium. In D. Llinares, N. Fox \& R. Berry (Eds.). Podcasting: New Aural Cultures and Digital Media (pp. 173-188). Basingstoke: Palgrave Macmillan. https://doi.org/10.1007/978-3-319-90056-8

Waldmann, E. (2020). From storytelling to storylistening: How the hit podcast S-Town reconfigured the production and reception of narrative nonfiction. Ex-centric Narratives: Journal of Anglophone Literature, Culture and Media, (4), pp. 28-42. https://doi.org/10.26262/exna.v0i4.7913

Ziengs, E. (2019). Dansk Podcast Analyse 2019 - bagom danske podcastere 2019. Frederiksberg: Nochmal Consulting.

Ægidius, A. (2017). Håndteringen af musikfiler i krydsfeltet mellem downloading og streaming - En unders $\varnothing$ gelse af hverdagens digitale musikbrug og remedieringen af musikformater. PhD dissertation. Institute for Culture Study, University of Southern Denmark. Odense.

\section{Podcasts}

Det tomme magasin (2019-). Martin Nørgaard and Elias Ehlers, Denmark, DR. Accessed 10 September, 2020, via https://www.dr.dk/radio/p3/det-tomme-magasin

Fries Before Guys (2016-). Josephine Kuhn and Nanna Hovgaard, Denmark, Podland. Accessed 10 September, 2020, via https://podtail.com/da/podcast/FBG-before-guys/

My brother, my brother \& me (2020). Justin, Travis, and Griffin McElroy. Accessed 24 November, 2020, via https://www.themcelroy.family/mbmbam

Perfekt Uperfekt (2018-). Katrine Gisinger, Denmark, Podland. Accessed 10 September, 2020, via https://podtail.com/da/podcast/perfekt-uperfekt/

StartUp (2014-). Alex Blumberg, US, Gimlet Media. Accessed 10 September, 2020, via https://gimletmedia.com/shows/startup.

The Pen Addict (2014). Brad Dowdy and Myke Hurley. Accessed 10 September, 2020, via https://www.relay.fm/penaddict

\section{Online articles and websites}

Apple (2020, 20 November). Retrieved from

https://podcasts.apple.com/us/podcast/apple-news-today/id1473872585

Anchor (2020, 5 September). Retrieved from https://anchor.fm/

Carmen, A. (2020, 14 October). Spotify will let its podcast hosts include full songs in their shows. The Verge. Retrieved from https://www.theverge.com/2020/10/14/21514855/spotify-music-podcast-format-anchor-listen

Cridland, J. (2020a, 11 May). With Spotify and Joe Rogan, what now for podcasting's open ecosystem? Medium. Retrieved from https://medium.com/@JamesCridland/with-spotify-and-joe-rogan-whatnow-for-podcastings-open-ecosystem-19c2032c17ee

Cridland, J. (2020b, 17 September). Podcasts in Amazon Music. Retrieved from https://podnews. net/article/amazon-music-podcasts?utm_campaign=spiri_podcasts_podcasting\&utm_ medium=email\&utm_source=Revuepct.20newsletter

Edison Research (2019). Comedy, news, and society and culture podcasts most listened to-genres in podcasting. Accessed 5 September, 2020, via https://www.edisonresearch.com/comedy-news-and-societyand-culture-podcasts-most-listened-to-genres-in-podcasting/ 
Article: Independent podcasts on the Apple Podcasts platform in the streaming era

Heise, N. (2014). On the shoulders of giants? How audio podcasters adopt, transform and re-invent radio storytelling. In MOOC Transnational Radio Stories. https://doi.org/10.13140/RG.2.1.4930.4089

Holt, K. (2018, 4 October). Spotify opens up its podcasts section to all. Engadget.com. Retrieved from https://www.engadget.com/2018-10-04-spotify-podcasts-beta.html?

Misener, D. (2019, December 5). Podcast episodes got shorter in 2019. Retrieved from https://blog.pacificcontent.com/podcast-episodes-got-shorter-in-2019-69e1f3b6c82f

Misener, D. (2018, July 4). Podcasters, have you looked at your secondary categories lately? Retrieved from https://blog.pacific-content.com/podcasters-have-you-looked-at-your-secondary-categories-lately7f9b978650aa

Podimo.com (2020, 3 August). Retrieved from https://Podimo.com/dk/podcast/

Podcastindex.dk (2021, 4 February). Retrieved from https://podcastindex.dk/

Podtrac (2021, 4 February). Retrieved from http://analytics.podtrac.com/podcast-rankings

Newman, N. \& Gallo, N. (2020). Daily News Podcasts: Building New Habits in the Shadow of Coronavirus. Reuters Institute for the Study of Journalism, University of Oxford. Accessed 23 October, 2020, via https://reutersinstitute.politics.ox.ac.uk/sites/default/files/2020-11/Newman\%20and\%20Gallo\%20-\%20 Podcasts\%20and\%20the\%20Impact\%20of\%20Coronavirus\%20FINAL\%20\%282\%29.pdf

Slots- og Kulturstyrelsen (2019). Mediernes udvikling i Danmark - Radio og podcast 2019. Accessed 28 October, 2020, via https://mediernesudvikling.slks.dk/fileadmin/user_upload/dokumenter/medier/ Mediernes_udvikling/2019/Radio_og_podcast/PDF-filer_Radio_og_podcast/Radio_og_podcast_2019_ny.pdf

Statcounter (2020). Mobile operating system in Denmark. Accessed 5 September, 2020, via https:// gs.statcounter.com/os-market-share/mobile/denmark

Freja Sørine Adler Berg PhD Fellow 